Check for updates

Cite this: RSC Adv., 2017, 7, 29938

Received 18th April 2017

Accepted 4th June 2017

DOI: 10.1039/c7ra04343k

rsc.li/rsc-advances

\title{
A highly effective Ag-RANEY® nickel hybrid catalyst for reduction of nitrofurazone and aromatic nitro compounds in aqueous solution
}

\begin{abstract}
Alireza Khorshidi (D) * and Bahareh Ghorbannezhad
RANEY® nickel reduced $\mathrm{Ag}^{+}$ions to form ultrafine spherical silver nanoparticles over itself, and the obtained hybrid material was used as catalyst for efficient and selective reduction of aromatic nitro compounds, and nitrofurazone as a non-aromatic example, in aqueous solution by using $\mathrm{NaBH}_{4}$ as reducing agent. Other silver nanostructures with different morphologies such as silver nano-flowers were also prepared and their efficiency in the reduction process was evaluated. Ag-RANEY® nickel catalyst however, had superior advantages including mild reaction conditions, higher conversion yield, and reduction in aqueous solution at near ambient temperature. The catalyst was also recoverable and showed $5 \%$ decrease in efficiency after six successive runs.
\end{abstract}

\section{Introduction}

Nitroaromatic compounds are generally prepared via nitration of simple aromatic compounds ${ }^{1}$ and are extensively being used in various industries such as plastics, dyeing, agriculture, etc. As a result, nitroaromatic compounds are usually present in industrial effluents and agricultural waste water. ${ }^{2}$ Presence of these compounds in this waste, even in small quantities, is highly undesirable and has drastic adverse effects on the environment and human beings. Hence, there is an ongoing demand for new methods of removal or conversion of these compounds to less harmful products. Anilines are an important class of precursors for the synthesis of pharmaceuticals, dyes, and other biologically active compounds such as Glu-P-1 and Trp-P-2, ${ }^{3-5}$ and can be produced by selective reduction of nitroaromatic compounds. While traditional methods such as reduction with iron powder in presence of hydrochloric or acetic acid ${ }^{6}$ are gradually being eliminated due to environmental issues, catalytic hydrogenation processes have emerged as more effective alternatives. Some of the recent reports in this context include application of silver nanoparticles stabilized by polyaminocyclodextrin, ${ }^{7} \mathrm{Fe}(\mathrm{II})$ complexes and nano zero-valent iron, ${ }^{8}$ gold nanoparticles, ${ }^{9} \mathrm{NaBH}_{4} / \mathrm{RANEY}^{\circledR}$ nickel, ${ }^{10} \mathrm{Ag}$ nanoparticles supported on cellulosic fibers, ${ }^{11}$ palladium nanoparticles, ${ }^{12}$ and platinum single-atom catalysts. ${ }^{13}$ Other reagents such as hydrazine/RANEY® ${ }^{\circledR}$ nickel, ${ }^{14} \mathrm{Na}_{2} \mathrm{~S} / \mathrm{NEt}_{4} \mathrm{Br},{ }^{15}$ $\operatorname{Sm}(0),{ }^{16} \mathrm{H}_{2} /$ RANEY ${ }^{\circledR}$ nickel, ${ }^{17}$ metal carbonyls such as $\mathrm{Mo}(\mathrm{CO}){ }_{6},{ }^{18}$ and $\mathrm{Pd} / \mathrm{Fe}$ bimetal nanoparticles embedded in P-doped mesoporous carbons, ${ }^{19}$ have also been reported. However, limitations associated with these methods, such as long reaction time, high

Department of Chemistry, Faculty of Sciences, University of Guilan, P. O. Box: 41335-1914, Iran. E-mail: khorshidi@guilan.ac.ir; Fax: +98 13333332 62; Tel: +989113397159

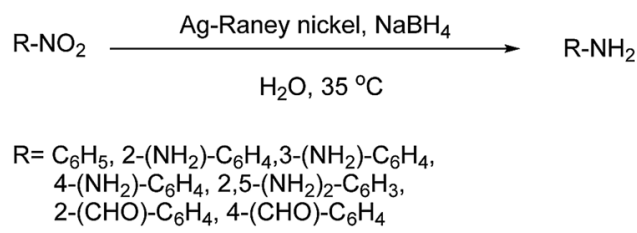

Scheme 1 Reduction of various nitro compounds in water at near ambient temperature catalyzed by Ag-RANEY® nickel.

temperature or pressure, use of harmful organic solvents, need of special apparatus and expensive reagents or catalysts, prevent their practical application. RANEY® nickel, on the other hand, is an outstanding catalyst in the field of transfer hydrogenation. ${ }^{20-23}$ Its performance in the catalytic hydrogenation of nitroaromatic compounds however, still needs to be improved. Hereby, we report a combination of silver nanoparticles and RANEY® nickel as an effective catalyst in the reduction of a variety of nitroaromatic compounds as well as nitrofurazone, as a non-aromatic example, by $\mathrm{NaBH}_{4}$ (Scheme 1).

\section{Experimental}

\section{Materials and methods}

RANEY®-nickel was purchased from W. R. Grace and Co. All of the other chemicals were purchased from Sigma-Aldrich and used without further purification. Flower-like silver nanoparticles were prepared according to the literature. ${ }^{24}$ Silver nanoparticles deposited over the surface of RANEY ${ }^{\circledR}$ nickel were prepared via two different methods. For the reduction of $\mathrm{Ag}^{+}$ions with $\mathrm{NaBH}_{4}$, the method of Mirkin, ${ }^{25}$ without using hydrogen peroxide and PVP was used. For the reduction of $\mathrm{Ag}^{+}$ ions with RANEY® nickel itself as a reducing agent, the 
following method was used. RANEY® nickel (100 mg) was dispersed in $500 \mathrm{~mL}$ of double distilled water for $15 \mathrm{~min}$ in a round-bottom flask located in an ultrasonic bath. Then the mixture was simultaneously stirred by means of a mechanical stirrer rotating at $1500 \mathrm{rpm}$ and $100 \mathrm{~mL}$ of $0.5 \mathrm{mM} \mathrm{AgNO}$ solution was injected at once. The trend of reduction was monitored by sodium chloride test. After $30 \mathrm{~min}$, the product (Ag-RANEY® nickel) was separated by centrifugation at $2000 \mathrm{rpm}$, washed with acetone and dried under reduced pressure.

General procedure for reduction of nitroaromatic compounds. To $100 \mathrm{~mL}$ of a $0.2 \mathrm{mM}$ solution of the corresponding nitroaromatic compound in water, $5 \mathrm{mg}$ of $\mathrm{Ag}$ RANEY ${ }^{\circledR}$ nickel catalyst was added and the suspension was stirred at $35{ }^{\circ} \mathrm{C}$ by a mechanical stirrer rotating at $1200 \mathrm{rpm}$. Then $1.0 \mathrm{~mL}$ of freshly prepared $0.04 \mathrm{M} \mathrm{NaBH}_{4}$ in water was added and the reaction proceeded until complete reduction of nitro groups as was monitored by measuring of the absorbance of the solution under investigation at $\lambda_{\max }$ of the nitro compound, after filtration of the catalyst.

\section{Instrumentation}

UV-Vis spectra were recorded on a Perkin Elmer LAMBDA 25 spectrophotometer. XRD measurements were performed by using a Philips X'pert diffractometer with mono chromatized $\mathrm{Cu} \mathrm{K} \propto$ radiation at $40 \mathrm{kV}$ and $20 \mathrm{~mA}$ (Ni filter, $2 \theta 10$ to $70^{\circ}$ with a step size of $0.05^{\circ}$ and a count time of $1 \mathrm{~s}$ ). Scanning electron micrographs were obtained on a Jeol JSM 6400. TEM images were obtained on a transmission electron microscope (TEMPHILIPS MC 10) with an acceleration voltage of $80 \mathrm{kV}$. ICPOES analysis was performed on a PerkinElmer Optima 8300 ICP-OES spectrometer.

\section{Results and discussion}

\section{Characterization of the catalysts}

Silver nanostructures with a drastically different morphology were prepared and their efficiency in reduction of nitroaromatic compounds was evaluated. Low-magnification SEM micrographs of the flower-like silver nanoparticles, Ag nanoparticles prepared by reduction with $\mathrm{NaBH}_{4}$, and those prepared by reduction with RANEY® nickel are shown in Fig. 1a-c. From Fig. 1a, it is clear that the obtained nanoflowers have rod-like tips of about 60-90 $\mathrm{nm}$ in diameter. Reduction of $\mathrm{Ag}^{+}$with $\mathrm{NaBH}_{4}$ on the other hand, resulted in aggregates of disordered silver nanoparticles (Fig. 1b) over the surface of RANEY® nickel. Reduction with RANEY® nickel however, resulted in aggregate free surfaces (Fig. 1c), and a closer look by a transmission

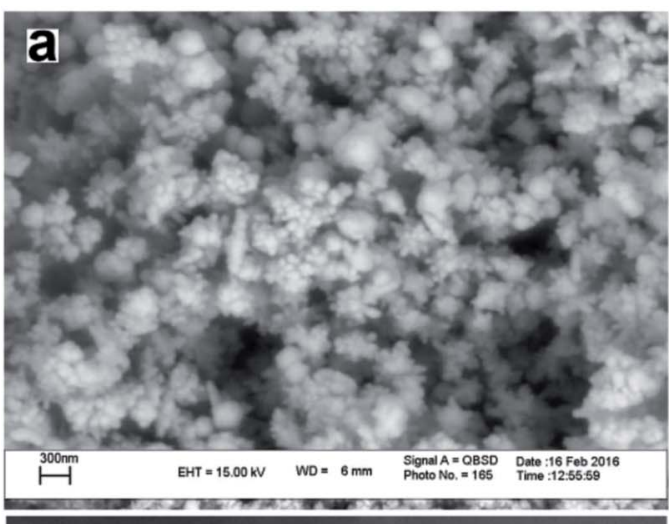

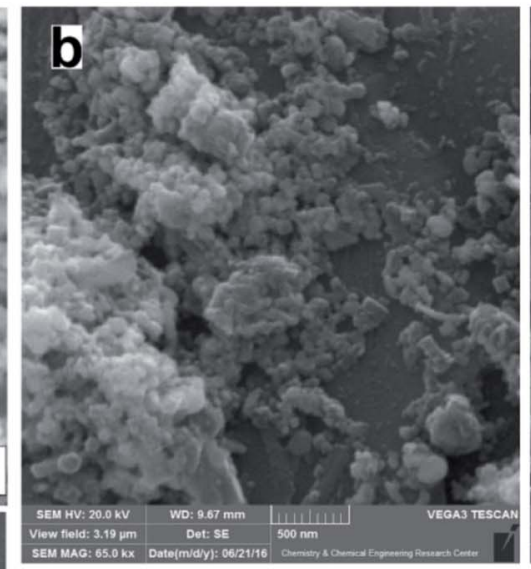
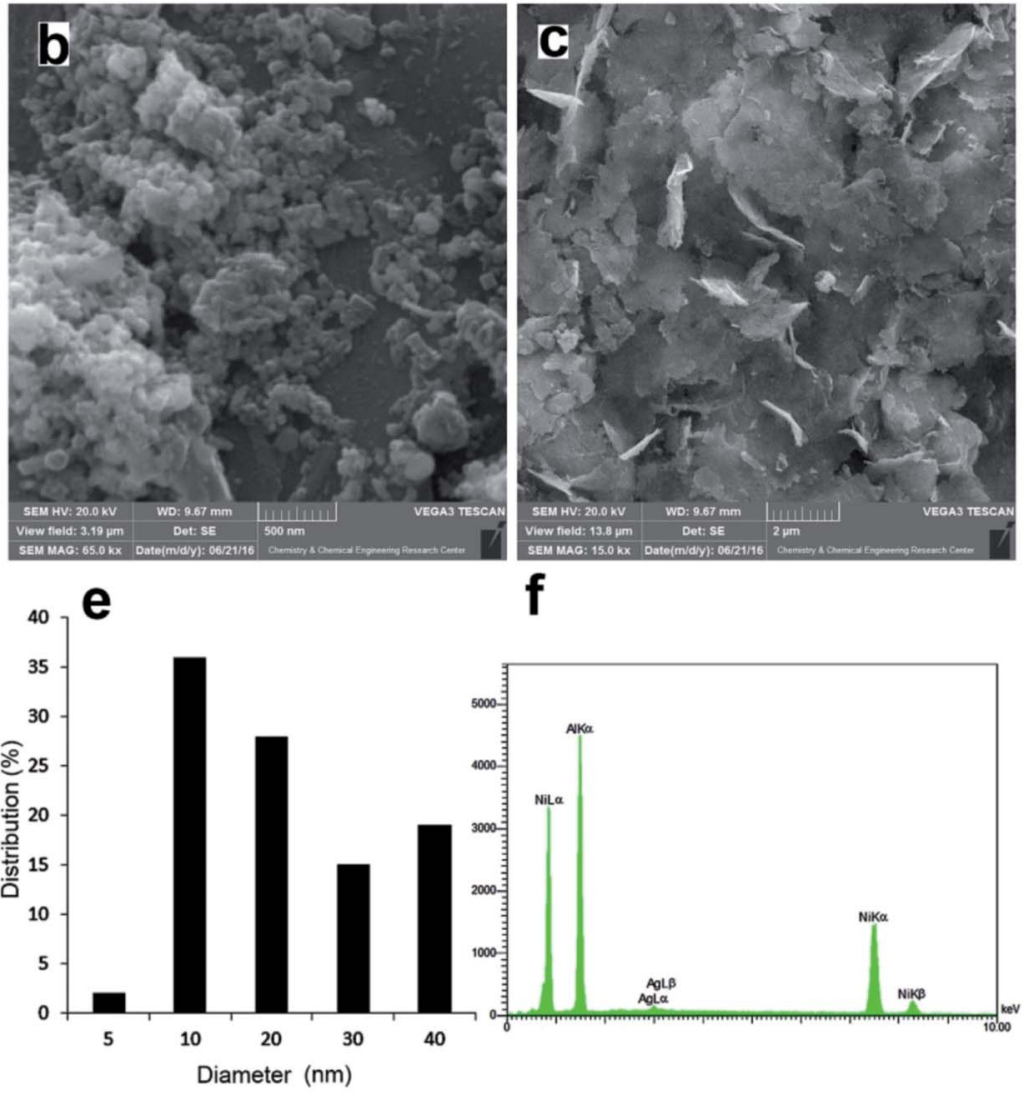

$\mathbf{f}$

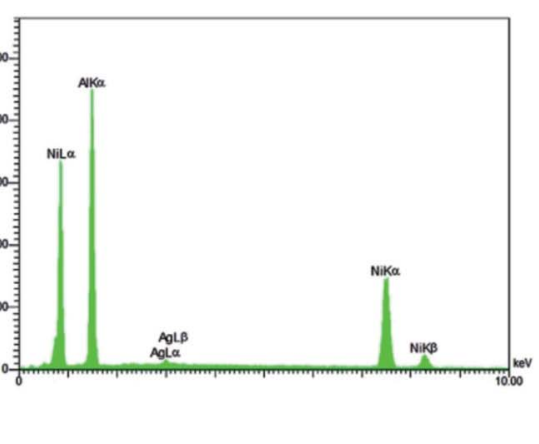

Fig. 1 SEM image of flower-like silver nanoparticles (a), aggregated Ag nanoparticles prepared by reduction with $\mathrm{NaBH}_{4}$ (b), aggregate free surface of $\mathrm{Ag}-\mathrm{RANEY} \otimes$ nickel catalyst prepared by reduction of $\mathrm{Ag}^{+}$with RANEY ${ }^{\circledR}$ nickel (c), and its TEM image (d) with corresponding particle size distribution chart (e) and EDX analysis (f). 
electron microscope revealed the formation of ultrafine spherical silver nanoparticles ranging from 10 to $40 \mathrm{~nm}$ throughout the entire surface (Fig. 1d) based on the corresponding size distribution chart (Fig. 1e). Energy dispersive X-ray analysis also, revealed the simultaneous presence of $\mathrm{Ni}, \mathrm{Al}$ and $\mathrm{Ag}$ (Fig. 1f).

In the XRD diffractogram of the flower-like silver nanoparticles (Fig. 2a), three peaks at $38^{\circ}, 44^{\circ}$ and $74^{\circ}$ correspond to 111, 200 and 220 planes of face-centered-cubic (FCC) silver on the basis of standard values in the card (JCPDS file no. 04-783). Moreover, formation of some hcp phase, based on the reflections at $36^{\circ}$ and $40^{\circ}$ indexed to (0004) and (1102) planes of hcp silver is evident. In the XRD pattern of the $\mathrm{Ag}$ nanoparticles prepared by reduction with RANEY® nickel (Ag-RANEY® nickel, Fig. 2b), in addition to the (111) and (200) reflections of $\mathrm{Ni}$ at $44.5^{\circ}$ and $52^{\circ}$, corresponding reflections of fcc silver were also present. Other peaks at $28.5^{\circ}, 46.5^{\circ}$ and $47.5^{\circ}$ correspond to alumina trihydrates. Generally, RANEY® nickel consists of metallic nickel, and aluminum as either metal or $\mathrm{Al}_{2} \mathrm{O}_{3} \cdot 3 \mathrm{H}_{2} \mathrm{O}$. The alumina trihydrates were identified as components of the

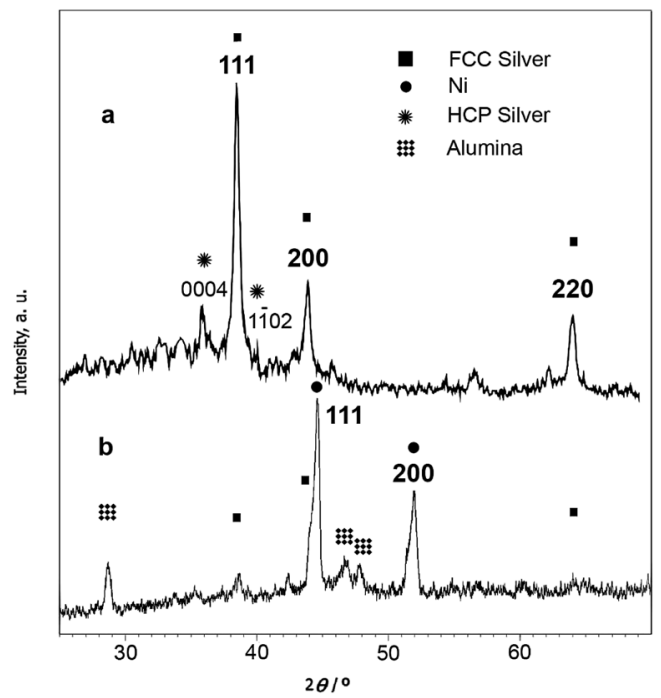

Fig. 2 XRD pattern of flower-like silver nanoparticles (a), and AgRANEY® nickel catalyst (b).

Table 1 Reduction of nitrobenzene with $\mathrm{NaBH}_{4}$ using different catalysts

\begin{tabular}{llll}
\hline Entry $^{a}$ & Catalyst type & $\begin{array}{l}\text { Catalyst } \\
\text { loading }(\mathrm{mg})\end{array}$ & $\begin{array}{l}\text { Apparent rate } \\
\text { constant, } k\left(\mathrm{~min}^{-1}\right)\end{array}$ \\
\hline 1 & None & - & 0.001 \\
2 & Flower-like Ag & 5 & 0.159 \\
& nanoparticles & & \\
3 & RANEY® nickel & 5 & 0.254 \\
4 & Ag aggregates on & 5 & 0.342 \\
& RANEY® nickel & & 0.435
\end{tabular}

${ }^{a}$ All of the reactions were carried out according to the general experimental procedure at room temperature.
RANEY® nickel and it has been shown that their crystalline structure does not dehydrate considerably during evacuation at elevated temperature. ${ }^{26}$ It should also be noted that the Ag content of the $\mathrm{Ag}-\mathrm{RANEY}{ }^{\circledR}$ nickel catalyst was determined by ICP-OES method and the result was similar to that obtained by EDX analysis ( $0.83 \mathrm{w} \%$ vs. $0.71 \mathrm{w} \%)$.

Taking into account the requirements of sustainable and green chemistry, including mild reaction conditions, using non-toxic solvents and in situ preparation of reactive components such as hydrogen, reduction of nitrobenzene in water was selected as a model reaction to determine the optimum conditions such as catalyst type, catalyst loading, $\mathrm{pH}$, and temperature. $\mathrm{NaBH}_{4}$ was used as the source of hydrogen because it is fairly an inexpensive reagent. Control experiments showed that the reduction efficiency depends on the catalyst type. From Table 1 it is clear that under the same conditions, Ag-RANEY® nickel resulted in the best reduction efficiency in terms of the apparent rate constant being calculated as $\ln C / C_{0}=-k t$ (where $C$ is the residual and $C_{0}$ is the initial concentration of the nitrobenzene, measured at $269 \mathrm{~nm}$ at room temperature in $\mathrm{pH}$ $=7.0$ ). Higher activity of Ag-RANEY® nickel may be attributed to the uniform distribution of ultrafine silver nanoparticles which provides higher surface area for these nanoparticles, and more active sites would be available for the catalytic reduction.

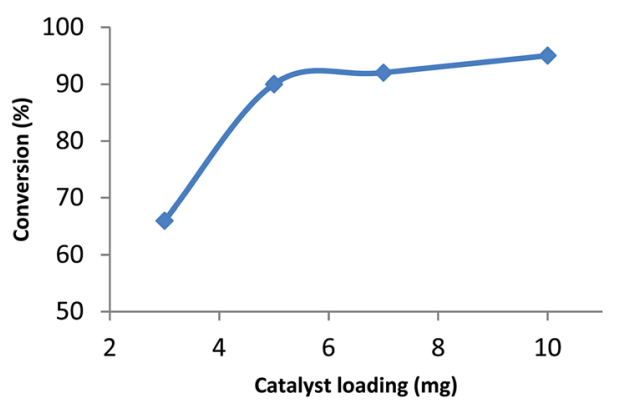

Fig. 3 Reduction efficiency in terms of conversion (\%) vs. catalyst loading, after 5 min under general experimental conditions.

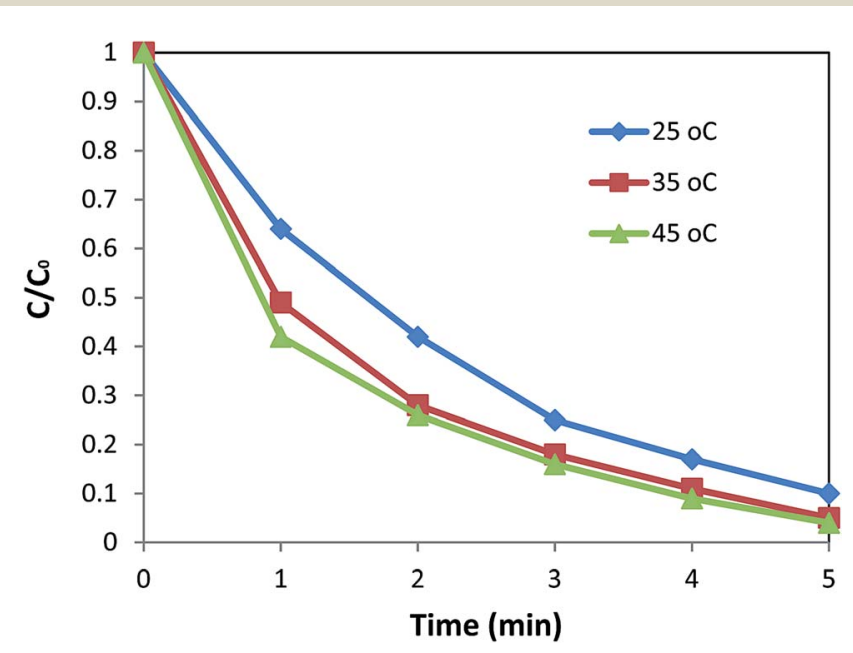

Fig. 4 Trend of nitrobenzene reduction at different temperatures. 


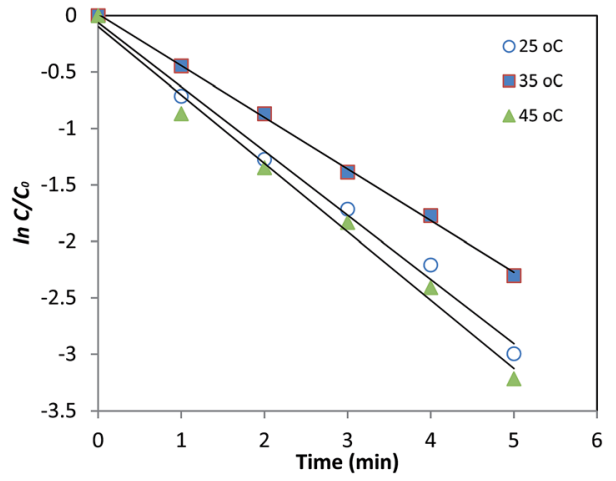

Fig. 5 Plot of $\ln C / C_{0}$ vs. time at 25,35 , and $45^{\circ} \mathrm{C}$ for reduction of nitrobenzene in presence of $5.0 \mathrm{mg}$ of the catalyst.

It was also found that reduction efficiency depends on the catalyst loading. Fig. 3 shows that increase in the catalyst loading from 3.0 to $10.0 \mathrm{mg}$ results in a non-linear increase in the reduction efficiency. Based on these data, $5.0 \mathrm{mg}$ of the AgRANEY® nickel catalyst was selected as the optimum amount.

In order to investigate the effect of temperature on the reduction of nitrobenzene, the reaction was carried out at different temperatures of 25,35 , and $45{ }^{\circ} \mathrm{C}$ under an optimized catalyst loading of $5.0 \mathrm{mg}$, and $C / C_{0} v s$. time was plotted. From Fig. 4, it is clear that an increase in the temperature results in slightly better efficiency.

It was also found that the reduction of nitrobenzene follows a pseudo first order kinetic with the apparent rate constant being calculated as $\ln C / C_{0}=-k t$. The value of $k$ for $5.0 \mathrm{mg}$ of the catalyst was found to be $0.457,0.568$, and $0.605 \mathrm{~min}^{-1}$ at 25 , 35 , and $45{ }^{\circ} \mathrm{C}$, respectively (Fig. 5). Based on these data, $35{ }^{\circ} \mathrm{C}$ was selected as the optimum temperature for reduction of nitroaromatic compounds, which in turn, has the advantage of proximity to the ambient temperature.

With the optimized conditions in hand, a variety of nitroaromatic compounds were used to evaluate generality and

Table 2 Reduction of various nitroaromatic compounds employing $\mathrm{Ag}-\mathrm{RANEY} \otimes$ nickel/ $\mathrm{NaBH}_{4}$ in aqueous solution

\begin{tabular}{|c|c|c|c|}
\hline Entry $^{a}$ & Nitroaromatic compound & Product $^{b}$ & $\begin{array}{l}\text { Apparent rate } \\
\text { constant, } k\left(\min ^{-1}\right)\end{array}$ \\
\hline 1 & & & 0.568 \\
\hline 2 & & & 0.386 \\
\hline 3 & & & 0.229 \\
\hline 4 & & & 0.528 \\
\hline 5 & & & 0.124 \\
\hline 6 & & & 0.139 \\
\hline 7 & HC & & 0.061 \\
\hline & & & 0.035 \\
\hline
\end{tabular}

${ }^{a}$ All of the reactions were carried out according to the general experimental procedure. ${ }^{b}$ Products were identified from their MS spectra in comparison with authentic samples. 
<smiles>NC(=O)N/N=C/c1ccc([N+](=O)[O-])o1</smiles>

Fig. 6 Nitrofurazone.

scope of this reductive protocol, and typical results are shown in Table 2.

In order to extend applicability of the Ag-RANEY® nickel/ $\mathrm{NaBH}_{4}$ protocol to non-aromatic nitro compounds, nitrofurazone (Fig. 6) was selected due to its contribution in carcinogenesis.

Nitrofurazone is a broad-spectrum antibiotic used in livestock, and has been detected in tissues and milk of animals. ${ }^{27,28}$ Significant correlation between nitrofurazone reduction and cellular DNA damage has been reported. ${ }^{29}$ Thus reduction of nitrofurazone residues may prevent release of this drug into the animal food and subsequent risk to human health. When 100 $\mathrm{mL}$ of a $0.2 \mathrm{mM}$ solution of nitrofurazone in water was treated with $5 \mathrm{mg}$ of $\mathrm{Ag}-\mathrm{RANEY}{ }^{\circledR}$ nickel catalyst and $1.0 \mathrm{~mL}$ of freshly prepared $0.04 \mathrm{M} \mathrm{NaBH}_{4}$ at $45{ }^{\circ} \mathrm{C}$, a continuous change in the UV-Vis spectrum of the solution was observed. Fig. 7 shows the recorded spectra after 15, 30, 45 and 60 min of stirring of the reaction mixture. Clearly, the band at $324 \mathrm{~nm}$ originating from the extended conjugated structure of nitrofurazone tends to disappear, while a distinct evolution in the band at $220 \mathrm{~nm}$, corresponding to $\mathrm{n} \rightarrow \pi^{*}$ transitions of $\mathrm{NH}_{2}$ groups, was observed. These changes, coincides with the color change of the solution from yellow to colorless. Under these circumstances, $89 \%$ of the starting nitrofurazone was reduced based on the measurement of the absorbance of the solution at $324 \mathrm{~nm}$.

In order to evaluate reusability of the catalyst, reduction of nitrobenzene was carried out in presence of the recycled catalyst. Fig. 8 shows the reduction efficiency against successive reaction runs. As it is clear, after six runs, only 5\% decrease in efficiency in terms of conversion percent was observed.

To get an insight into the reaction mechanism of reduction of nitrobenzene, we assumed that if the reaction proceeds via polar intermediates such as nitrosobenzene, phenylhydroxylamine and hydrazine, then each of these intermediates must follow the same path, leading to the same product. Formation of such intermediates is often observed with many other

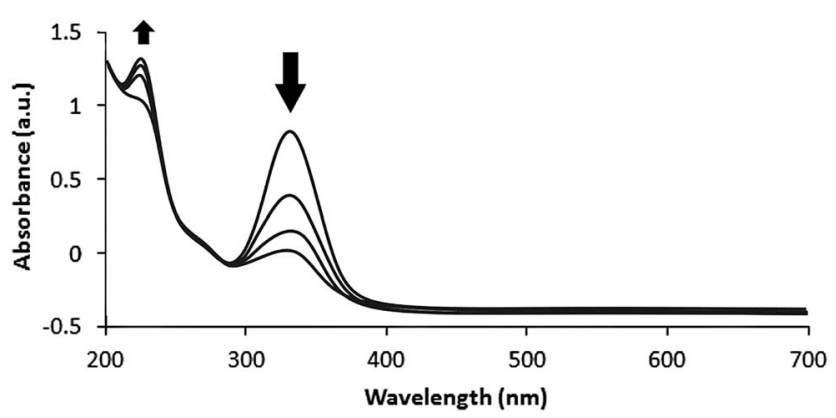

Fig. 7 Spectral changes of nitrofurazone solution $(0.2 \mathrm{mM})$ at 15,30 , 45 and 60 min time intervals.

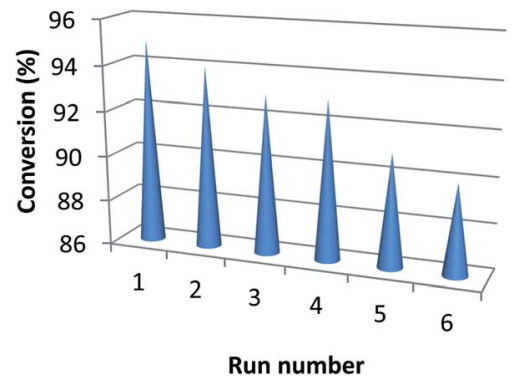

Fig. 8 Reusability of the recycled catalyst.

reducing agents. ${ }^{\mathbf{1 6}, 30}$ When nitrosobenzene or phenylhydroxylamine was treated with $\mathrm{Ag}-\mathrm{RANEY}{ }^{\circledR}$ nickel and $\mathrm{NaBH}_{4}$ in aqueous solution at $35{ }^{\circ} \mathrm{C}$, the final product was aniline and it can be concluded that the following reaction path rationalized the overall reduction.

$$
\mathrm{Ph}-\mathrm{NO}_{2} \rightarrow \mathrm{Ph}-\mathrm{NO} \rightarrow \mathrm{Ph}-\mathrm{NHOH} \rightarrow \mathrm{Ph}-\mathrm{NH}_{2}
$$

\section{Conclusions}

In conclusion, we have devised a new catalyst based on silver nanoparticles distributed over the surface of RANEY® nickel for efficient reduction of nitro compounds in aqueous solution under mild conditions. Highlights of the present work include near ambient reaction temperature, use of water as a green solvent, in situ production of the reducing agent from readily available $\mathrm{NaBH}_{4}$, and above all, reusability which promises minimization of the catalyst waste.

\section{Acknowledgements}

The authors are grateful to the Research Council of University of Guilan for the partial support of this study.

\section{References}

1 J. P. Adams and J. R. Paterson, J. Chem. Soc., Perkin Trans. 1, 2000, 3695-3705.

2 H.-Y. Lee and M. An, Bull. Korean Chem. Soc., 2004, 25, 17171719.

3 H.-U. Blaser, Science, 2006, 313, 312-313.

4 A. Corma, P. Concepción and P. Serna, Angew. Chem., 2007, 119, 7404-7407.

5 T. Sugimura, K. Wakabayashi, H. Nakagama and M. Nagao, Cancer Sci., 2004, 95, 290-299.

6 C. A. Merlic, S. Motamed and B. Quinn, J. Org. Chem., 1995, 60, 3365-3369.

7 M. Russo, F. Armetta, S. Riela, D. C. Martino, P. L. Meo and R. Noto, J. Mol. Catal. A: Chem., 2015, 408, 250-261.

8 S. He, H. Niu, T. Zeng, S. Wang and Y. Cai, ChemistrySelect, 2016, 1, 2821-2825.

9 H. Zhu, X. Ke, X. Yang, S. Sarina and H. Liu, Angew. Chem., 2010, 122, 9851-9855. 
10 I. Pogorelić, M. Filipan-Litvić, S. Merkaš, G. Ljubić, I. Cepanec and M. Litvić, J. Mol. Catal. A: Chem., 2007, 274, 202-207.

11 F. Torkamani and S. Azizian, J. Mol. Liq., 2016, 214, 270-275.

12 N. Mei and B. Liu, Int. J. Hydrogen Energy, 2016, 41, 1796017966.

13 H. Wei, X. Liu, A. Wang, L. Zhang, B. Qiao, X. Yang, Y. Huang, S. Miao, J. Liu and T. Zhang, Nat. Commun., 2014, 5, 5634 .

14 F. Yuste, M. Saldaña and F. Walls, Tetrahedron Lett., 1982, 23, 147-148.

15 G. D. Yadav and S. V. Lande, Adv. Synth. Catal., 2005, 347, 1235-1241.

16 C. Yu, B. Liu and L. Hu, J. Org. Chem., 2001, 66, 919-924.

17 M. Viktor, D. Ilavsky and J. Salon, Molecules, 1997, 2, M13.

18 S. Iyer and G. M. Kulkarni, Synth. Commun., 2004, 34, 721725.

19 Y. Zhou, L. Tang, G. Yang, G. Zeng, Y. Deng, B. Huang, Y. Cai, J. Tang, J. Wang and Y. Wu, Catal. Sci. Technol., 2016, 6, 1930-1939.
20 H. D. Burge, D. J. Collins and B. H. Davis, Ind. Eng. Chem. Prod. Res. Dev., 1980, 19, 389-391.

21 P. Gallezot, P. Cerino, B. Blanc, G. Fleche and P. Fuertes, J. Catal., 1994, 146, 93-102.

22 H. Adkins and H. R. Billica, J. Am. Chem. Soc., 1948, 70, 695698.

23 P. Fouilloux, Appl. Catal., 1983, 8, 1-42.

24 T. Liu, D. Li, D. Yang and M. Jiang, Langmuir, 2011, 27, 62116217.

25 G. S. Métraux and C. A. Mirkin, Adv. Mater., 2005, 17, 412415.

26 S. Robertson and R. Anderson, J. Catal., 1971, 23, 286-294.

27 E. Sugden, A. Macintosh and A. Vilim, J. - Assoc. Off. Anal. Chem., 1983, 66, 874-880.

28 A. Vilim and A. MacIntosh, J. - Assoc. Off. Anal. Chem., 1979, 62, 19-22.

29 P. L. Olive, Chem.-Biol. Interact., 1978, 20, 323-331.

30 Q. X. Shi, R. W. Lu, K. Jin, Z. X. Zhang and D. F. Zhao, Chem. Lett., 2006, 35, 226-227. 